\title{
APPROACHES AND METHODOLOGIES TO SUPPORT CRITICAL REFLECTION
}

\author{
Jean Claude Callens, VIVES University of Applied Sciences, Belgium
}

\section{Introduction}

During their studies, pre-service teachers are continually asked to reflect (Calderhead \& Gates, 1993; Korthagen \& Vasalos, 2005; Rodgers, 2002). In teacher education a goal of reflection is to change beliefs about teaching in order to improve practice, and therefore there is a strong connection between reflection and actions of students on the workplace.

It does not seem obvious that students in teacher education reach a critical level in their reflections (Bean \& Stevens, 2002). According to Bean and Stevens (2002) effective scaffolding of a reflection process encompasses a number of key features within cognitive and emotional domains. Cognitive features include for instance using hints and leading questions to develop self-regulation. Emotional features include for instance providing a safety net to allow for mistakes. In this study we focus on cognitive features and search for an approach/methodology that may support a reflection process.

\section{Approaches and methodologies to reflect}

There are different approaches and methodologies to support students to write their reflections. According to Rogers (2001) the number of steps in the different approaches to reflect varies from zero to eight. Some view the steps in a reflection process as sequential (Seibert \& Daudelin, 1999), while others contend that the steps of a reflective process do not need to follow any particular order (Schön, 1983). In this contribution, an approach that contains guidelines that may be considered sequential and step-by-step-structured is described as a linear approach to reflect. In contrast, an approach that does not include sequential, step-by-step-structured guidelines is described as a non-linear approach (van Eekelen, Boshuizen, \& Vermunt, 2005).

Besides variations in approaches to reflect, there are also variations in methodologies to support reflection (Callens \& Elen, 2012). In line with Callens (2012) we distinguish in this contribution methodologies that are (a) primarily language based or (b) primarily image based and thus more multimedial.

The writing of a learning journal and digital storytelling may be considered as examples of respectively primarily language and primarily image-based methodologies to support reflection. A learning journal is described as a hand-written note that may contain thoughts, 
reflections, feelings, personal opinions, hopes and fears regarding an educational experience (Mc Garr \& Moody, 2010). Banaszewski defines digital storytelling as "The practice of combining personal narrative with multimedia (images, audio and text) to produce a short autobiographical movie" (Banaszewski, 2005; p.1).

It is possible to vary the degree of structure (linear and non-linear approach to reflect) within each of the mentioned methodologies to support reflection (learning journal and digital journal). With the distinction between (a) the linear and non-linear structured approach and (b) primarily language and primarily image based methodologies to reflect 4 combinations are indicated (=linear and non-linear structured learning journal/digital storytelling).

\section{Research questions}

In this study we examine which combination of approach to reflect (cf. degree of structure) and methodology to reflect (cf. primarily language and primarily image based) most effectively supports critical reflection. This leads to the following research questions:

- To what extent do student teachers reflect critically?

- Is there an impact of approach to reflect on the degree of critical reflection?

- Is there an impact of methodology to reflect on the degree of critical reflection?

- Is there an interaction effect between an approach and methodology to reflect on the degree of critical reflection?

\section{Design of the study}

In order to determine which combination of approach and methodology to reflect most effectively supports the writing of reflection assignments, two studies were conducted. In both studies an experiment was carried out with respectively a pre-test post-test control group design and a post-test only control group design. In each study: (a) participants were student teachers, (b) the theoretical model of Kelchtermans was used to describe critical reflection, (c) the same procedure was used in order to determine the degree of critical reflection in the written reflection assignments, and (d) in both studies variations of the degree of structure (cf. approach to reflect) with respectively a learning journal and a digital storytelling were used.

\section{Participants}

In total 164 student teachers participated in the two studies. In the first study participants were 63 primary school student teachers and 101 secondary student teachers in the second. All participants were freshmen.

\section{Material and procedure}

Based on the results of an empirical study, Callens (2012) concludes that leading questions may influence the reflections that students make (see also Lai \& Calandra, 2010). Therefore, in both studies the same leading questions were used, but the presentation of these questions depended on the condition. With a more linear structured approach to reflect, the leading 
questions were presented according to the ALACT model of Korthagen. The ALACT model contains 5 sequential steps (Action, Looking back, Awareness of essential aspects, Creating alternative methods of action, and Trial) (Korthagen \& Vasalos, 2002). In a non-linear approach to reflect there was no step-by-step structuring of the leading questions.

The procedures varied. In the first study, students were notified of the experiment by their lecturers. Then, during an information session the participants were given further explanation. There were three class groups, and the same explanation was given by the same person. Afterwards, participants got guidelines for the first reflection assignment (pre-test) by e-mail. The guidelines in the first reflection assignment were the same for all participants (= non-linear structured digital story). Participants were asked to reflect upon a situation (a situation which they assess as difficult) in which they explained something (=content, a skill, a game...) to someone or to a group. Participants were asked to reflect by making a digital story. Because participants were freshmen, it could not be said with certainty that they had sufficient ICT skills to use multimedia in their digital stories. Therefore, a variant of digital storytelling was used and the students were asked to write a digital comic with a Word template. Participants were asked to explain the comic in a speech balloon. In addition to the reflection assignment, the first mail also contains a worked-out example. The second reflection assignment (post-test) was sent with an email after participants had finished the first assignment. The second reflection assignment varied according to the condition participants were randomly assigned to (cf. linear or non-linear structured digital story).

In the second study, students were notified of the experiment by their lecturers. Then the guidelines to make the reflection assignments were sent by email to the participants.

In all conditions, the same worked-out example was used, but the presentation varied according to the condition (whether or not linear structured). The subject of reflection was the same as in the first study but in the second study participants were asked to reflect with a primarily language based methodology, and were asked to write a learning journal (instead of the primarily image based methodology, cf. digital comic in the first study).

In the first study 154 and in the second 126 students were invited to participate. An individual randomization was used. Drop-out and the fact that uncompleted reflections were not taken in the analysis, lead to the fact that in the first study reflections of 101, and in the second of 63 participants were taken in the analysis. Due to the drop-out the conditions used in the two studies contains a different number of participants.

\section{Data analysis}

Similar to other approaches to determine the degree of critical reflection (see Granberg, 2010; Carrington \& Selva, 2010), a framework was used as coding scheme. This framework is based on the dimensions and domains described by Kelchtermans (2001; 2009).

In both studies, the approach used is based on the method described by Van Beirendonck (1998) to assess competences in an assessment centre. Marking in this context means that if, 
in a reflection by a participant, one element refers to a dimension or a domain of the mentioned framework, the participant received score one, with two elements score two, and so on.

In the first study (with a pre-test post-test control group design) the reflections from the posttest were analysed, in the second (with a post-test only control group design) all reflections were analysed. This means that a total of 164 reflections in the secondary data analysis were taken in the analysis.

When participants reflected through the writing of a learning journal, this journal was analysed. Because images are difficult to interpret without an explanation of the student (Briell, Elen, Depaepe, \& Clarebout, 2010), the analysis of the digital stories was based on the speech balloon, in which participants explain the comic.

Due to the large amount, all reflections in both studies were scored by only one assessor. However, to calculate the inter-rater reliability, in each study 40 reflections were scored by a second assessor. Each of the assessors marked blindly for condition using the coding scheme.

Because the variables are at a ratio scale, the inter-rater reliability was verified by calculating the correlation (using Pearson's correlation coefficient) (Evers \& Sermeus, 1998), between the scores of both assessors for: the technical and emotional dimensions, for the political and moral dimensions and for the personal interpretative framework. The correlation coefficients are between 0.78 and 1.00. Because a relatively high inter-rater reliability score was determined, the score of the first assessor - whom analysed all reflections - was taken as result.

\section{Results}

To answer the first research question, the results of the first study (in which students reflect by writing a digital story) reveals that participants score low on critical reflection (mean $=0.34 ; \mathrm{SD}=0.77$ ). In the second study (with a learning journal) the mean score is higher but still low (mean $=0.68$; $S D=0.82$ ). In both studies a high SD was found. Overall (results of both studies taken together in the analysis) the mean score is low and there is a high SD $($ mean $=0.47$; $\mathrm{SD}=0.81)$.

To answer the second research question, a one-way ANOVA (with approach to reflect as independent variable and degree of critical reflection as dependent variable) was conducted. For the first study, no significant results could be retrieved $(F(1,99)=0.22$, $\left.\mathrm{p}=0.64, \eta_{\mathrm{p}}{ }^{2}=0.00\right)$. Analysis of the second study reveals a significant weak-to-moderate (according to the guidelines of Nijdam, 2003) main effect of approach to reflect on critical reflection $\left(\mathrm{F}(1,61)=7.61, \mathrm{p}=0.00, \eta_{\mathrm{p}}{ }^{2}=0.11\right)$. When participants reflect with a linear structured learning journal (mean $=0.97, \mathrm{SD}=0.96$ ), they score better on the degree of critical reflection than when they reflect with a non-linear structured learning journal (mean $=0.42, \mathrm{SD}=0.56)$. 
To exam the impact of methodology to reflect and to check for interaction between approach and methodology to reflect on critical reflection (cf. third and fourth research question), the results of both studies were taken together in the analysis. A one-way ANOVA shows a significant, weak-to-moderate main effect of methodology to reflect $(F(1,162)=7.35$, $\left.\mathrm{p}=0.00, \eta_{\mathrm{p}}{ }^{2}=0.04\right)$ on the degree of critical reflection. As mentioned earlier, when participants reflect with a learning journal (mean $=0.68, \mathrm{SD}=0.82$ ) they score better than when they reflect by writing a digital story (mean $=0.34, \mathrm{SD}=0.77$ ). Finally, a two-way ANOVA (with approach and methodology to reflect as independent and degree of critical reflection as dependent variables) reveals no interaction effect between approach and methodology to reflect on the degree of critical reflection.

A descriptive analysis give a more detailed view of participants' mean scores (Table 1). The results reveal that a linear structured learning journal most effectively supports critical reflection; a non-linear structured digital storytelling is least effective.

Table 1: Score critical reflection related to the approaches/methodologies to reflect

\begin{tabular}{|c|c|c|c|}
\hline $\begin{array}{l}\text { Approach and methodology } \\
\text { to reflect }\end{array}$ & $\begin{array}{c}\text { Mean score on critical } \\
\text { reflection }\end{array}$ & SD & $\begin{array}{l}\text { Frequency of reflections } \\
\text { participants made }\end{array}$ \\
\hline $\begin{array}{l}\text {-Linear structured learning } \\
\text { journal }\end{array}$ & .97 & .96 & 30 \\
\hline $\begin{array}{l}\text {-Non-linear structured } \\
\text { learning journal }\end{array}$ & .42 & .56 & 33 \\
\hline -Linear structured digital story & .38 & .84 & 48 \\
\hline $\begin{array}{l}\text {-Non-linear structured digital } \\
\text { story }\end{array}$ & .30 & .72 & 53 \\
\hline Total & .47 & .81 & 164 \\
\hline
\end{tabular}

\section{Conclusion}

The results in this study reveal that the mean score of all reflections on critical reflection is low. This is in line with results from previous studies (Callens et al., 2012; El-Dib, 2007; Dinkelman, 2000).

Second, a high SD is observed. Because of this high SD, the assumption that learner characteristics may have an impact on the degree of critical reflection is - at least partly confirmed in this study. When asked what characteristics of the students can determine whether a student is able to reflect critically, we refer to Rogers. Rogers (2001) identifies readiness and willingness to engage in the process of reflection and refers to the work of Boud, Keogh and Walker, Dewey, Langer, Loughran, and Mezirow. The importance of willingness is also mentioned by Rodgers (2002), Walkington, Christensen, and Kock (2001) and Tann (1993). Furthermore, a research study conducted by Huy (2008) reveals that both epistemological beliefs and learning approaches may influence reflection processes. The assumed influence of willingness on the process of reflection is indirectly confirmed in a study conducted by Granberg (2010). The analysis of reflection reports (with blogs) and interviews with 13 preschool student teachers revealed that students that complete their 
reflection assignments only to obtain a degree, do not take enough time to commit themselves to the reflection process and thus to make deeper reflections (Granberg, 2010).

Third, it seems that a linear-structured approach to reflect more effectively supports critical reflection than a non-linear structured one. Several authors stress the importance of a more structured approach to reflect (Gibbs, 1981; Korthagen, Koster, Melief, \& Tigchelaar, 2002). According to Korthagen et al. (2002) student teachers sometimes hate to complete reflection assignments because thinking about oneself can be threatening. They argue that student teachers (especially externally oriented, less "reflective" students) are initially in need of much guidance and structure to compensate for (often unconscious) feelings of uncertainty. Bean and Stevens (2002) write that when reflection takes place without adequate guidance, students may see the process as yet another ritual and treat in a cursory fashion. According to Arrastia et al. (2014) pre-service teachers can reflect without guidance or scaffolding, but ill-structured assignments may not lead to deeper reflection.

Fourth, the lower score on digital storytelling (compared to a learning journal) can be explained by the idea that writing digital stories (or writing a comic strip) expects additional skills. According to Banaszewski (2005) digital storytelling requires students to develop enough visual literacy when they are asked to write a digital story. Visual literacy refers to understanding and using images. From this perspective, it seems that a sober methodology to reflect (like a learning journal) more effectively supports a reflection process than a complex methodology (like digital storytelling).

While the results of these two studies are revealing, a number of methodological issues are to be considered.

First, there are additional factors (than approach and methodology to reflect) of a learning environment that may influence the degree of critical reflection and should thus be considered as elements of a learning environment that support pre-service teachers in critical reflection. For instance, Rogers (2001) refers to the following contextual conditions: feedback, autonomy, interaction and facilitating opportunities so that appropriate challenges may emerge. Based on the results of this study, it is unclear what feedback participants have received from their lecturers, the degree of interaction they have had with their peers, and what specific initiatives lectures have taken to stimulate students to reflect. It is possible that these elements may have influenced the reflection of the participants and thus affected the (low) score of critical reflection obtained in this study. Furthermore, a supportive climate seems to be a vital condition in supporting a reflection process (Ramsey, 2010). In these studies, students from only one institution were asked to participate. It is not clear to what extent this institution aims to create a climate that encourages students to have a critical dialogue on their teaching practice and thus have enough confidence to write a reflection report. The results of this study do not clarify whether the low score for critical reflection is due to the students' abilities/characteristics or is affected by contextual conditions of a learning environment (or both). 
Second, in the first study participants were secondary school student teachers, in the second primary school student teachers. It is unclear whether the same result could be achieved in case participants in both studies followed the same program.

Third, the results in this study are obtained by analysis from only two experiments with different participants. Although there are a rather large number of participants, it seems that a longitudinal research with the same participants is needed to corroborate the results.

Last, we want to discuss the analysis of the data. In this study, the reflections used in the analysis are reports made by the participants after the 'action' (cf. reflection after action). This approach does raise at least three questions. First, reflection after action is always blended with the reflection that took place prior to and during the action (Ramsey, 2010). With the methodology used in this study, reflections made prior to and during the action are not taken into account. Second, it is unclear whether the participants were sufficiently motivated to write these reports. Third, it is assumed that students may have had difficulty in articulating their experiences in anything other than colloquial terms (Tann, 1993). For these three reasons, it is unclear whether these documents capture all of the reflections of the students.

Regarding further research, as the results of this study refer to freshmen further research could focus on the impact of approach and methodology to reflect with participants whom are more experienced.

Further, the data analysis in this study is based on a quantitative approach. Referring to earlier mentioned reasons (see discussion of analysis of the data) it would be interesting to repeat this study but use a qualitative approach to analyse the reflections participants write.

In conclusion, we recommend - based on the results of this study- a linear structured approach to support first year pre-service teachers when writing reflection assignments. Secondly, it seems that more complicated methodologies are inhibitory for the degree students reflect critically. Therefore, we endorse a simple (for instance text based methodology) to support student to reflect critically.

\section{References}

Akbari, R. (2007). Reflections on reflection: A critical appraisal of reflective practices in L2 teacher education. System, 35, 192-207.

Arrastia, M. C., Rawls, E. S., Brinkerhoff, E. H., \& Roehrig, A. D. (2014). The nature of elementary preservice teachers' reflection during an early field experience. Reflective Practice, 15(4), 427-444.

Banaszewski, T. (2005). Digital storytelling, supporting digital literacy in grades 4-12 (Unpublished master thesis). Georgia Institute of Technology. Retrieved from http://techszewski.blogs.com/techszewski/files/TB_thesis_2006_edits.doc

Bean, T. W., \& Stevens, L. P. (2002). Scaffolding reflection for preservice and inservice teachers. Reflective Practice, 3(2), 205-218. 
Briell, J., Elen, J., Depaepe, F., \& Clarebout G. (2010). The Exploration of Drawings as a Tool to Gain Entry to Students' Epistemological Beliefs. Electronic Journal of Research in Educational Psychology, 8(2), 655-688.

Calderhead, J., \& Gates, P. (Eds.) (1993). Conceptualizing reflection in teacher development. London: Falmer Press.

Callens, J. C., \& Elen, J. (2012). The impact of approach to reflection and learner control upon critical reflection. Reflective Practice, 12(4), 495-506.

Callens, J. C. (2012). Impact van reflectie-aanpak en learner control op kritisch reflecteren Doctoraatsproefschrift. Katholieke Universiteit Leuven, Faculteit Psychologie en Pedagogische Wetenschappen, Centrum voor Instructiepsychologie en -technologie, Leuven.

Carrington, S, \& Selva, G. (2010). Critical social theory and transformative learning: evidence in pre-service teachers' service-learning. Higher Education Research \& Development, 29(1), 45-57.

Dinkelman, T. (2000). An inquiry into the development of critical reflection in secondary teachers. Teaching and Teaching Education, 16(2), 195-222.

van Eekelen, I. M., Boshuizen, H., \& Vermunt, J. D. (2005). Self-regulation in higher education teacher learning. Higher Education, 50(3), 447-471.

El-Dib, M. (2007). Levels of Reflection in Action Research: An Overview and an Assessment Tool. Teaching \& Teacher Education: An International Journal of Research and Studies, 23(1), 24-35.

Evers, G., \& Sermeus, W. (1998). Betrouwbaarheid en validiteit van meetinstrumenten. In Evers, G. (Ed.), Meten van zelfzorg. Verpleegkundige instrumenten voor onderzoek en klinische praktijk. Leuven: Universitaire Pers.

Gibbs, G. (1981). Teaching Students to Learn, a student-centered approach. Milton Keynes: Open University Press.

Granberg, C. (2010). Social software for reflective dialogue: questions about reflection and dialogue in student teachers blogs. Technology, Pedagogy and Education, 19(3), 345-360.

Huy, P. (2008). Predicting change in epistemological beliefs, reflective thinking and learning styles: a longitudinal study. British Journal of Educational Psychology, 78(1), 75-93.

Korthagen, F., \& Vasalos, A. (2002). Niveaus in reflectie: naar maatwerk in begeleiding. VELON Tijdschrift voor Lerarenopleiders, 23(1), 29-38.

Korthagen, F., \& Vasalos, A. (2005). Levels in reflection: core reflection as a means to enhance professional growth. Teachers and Teaching: theory and practice,11(1), 47-71.

Korthagen, F., Koster, B., Melief, K., \& Tigchelaar, A. (2002). Docenten leren reflecteren. Systematische reflectie in de opleiding en begeleiding van leraren. Soest: Uitgeverij Nelissen. 
Lai, G., \& Calandra, B. (2010). Examining the effects of computer-based scaffolds on novice teachers' reflective journal writing. Educational Technology Research and Development, $58(4), 421-437$.

Mc Garr, O., \& Moody, J. (2010). Scaffolding or stifling? The influence of journal requirements on students' engagement in reflective practice. Reflective Practice, 11(5), 579-591.

Nijdam, A. (2003). Statistiek in onderzoek, beschrijvende technieken, deel 1. Groningen: Wolters Noordhoff.

Ramsey, S. (2010). Reflecting on the future, education in the third millennium. Curriculum and Teaching Dialogue, 5(2), 123-130.

Rodgers, C. (2002). Defining Reflection: Another look at John Dewey and reflective thinking. Teachers College Record, 104(4), 842-866.

Rogers, R. (2001). Reflection in higher education: a concept analysis. Innovative Higher Education, 26(1),37-57.

Schön, D. (1983). The Reflective Practitioner. How Professionals Think in Action. New York: Basic Books Inc.

Seibert, K. W., \& Daudelin, M. W. (1999). The role of reflection in managerial learning: Theory, research, and practice. Westport, CT: Quorum.

Tann, S. (1993). Eliciting Student Teachers Personal Theories. In J. Calderhead \& P. Gates (Eds.), Conceptualizing reflection in teacher development (pp. 53-69). London: Falmer Press.

Van Beirendonck, L. (1998). Beoordelen en ontwikkelen van competenties. Assessment centers, development centers en aanverwante technieken. Leuven/Amersfoort: Acco.

Walkington, J., Christensen, H., \& Kock, H. (2001). Developing critical reflection as a part of teaching training and teaching practice. European Journal of Engineering Education, 26(4), 343-350. 